\title{
Arterial to end-tidal carbon dioxide pressure gradient increases with age in the steep Trendelenburg position with pneumoperitoneum
}

\author{
Dae-Kee Choi, In-Gyu Lee, and Jai-Hyun Hwang \\ Department of Anesthesiology and Pain Medicine, College of Medicine, University of Ulsan, Asan Medical Center, Seoul, Korea
}

Background: Several factors affect the end-tidal carbon dioxide pressure $\left(\mathrm{P}_{\mathrm{ET}} \mathrm{CO}_{2}\right)$ and increase the arterial to endtidal carbon dioxide pressure gradient $\left(\mathrm{P}_{\mathrm{a}-\mathrm{ET}} \mathrm{CO}_{2}\right)$ during general anesthesia. We evaluated the relationship between age and $\mathrm{P}_{\mathrm{a}-\mathrm{ET}} \mathrm{CO}_{2}$ during pneumoperitoneum in the steep Trendelenburg position in patients undergoing robotassisted laparoscopic prostatectomy (RALP).

Methods: Ninety-two consecutive patients undergoing RALP were divided by age into a middle-aged (45-65 years) and an elderly ( $>65$ years) group. Anesthesia was standardized. Heart rate, mean arterial pressure, peak inspiratory pressure, lung compliance, minute ventilation, $\mathrm{P}_{\mathrm{a}} \mathrm{O}_{2}, \mathrm{P}_{\mathrm{ET}} \mathrm{CO}_{2}, \mathrm{P}_{\mathrm{a}} \mathrm{CO}_{2}$, and $\mathrm{P}_{\mathrm{a}-\mathrm{ET}} \mathrm{CO}_{2}$ were measured 10 min after intubation in the supine position without pneumoperitoneum (T0); and 10 (T1), 60 (T2), and 120 (T3) min after pneumoperitoneum in the Trendelenburg position.

Results: Although $\mathrm{P}_{\mathrm{ET}} \mathrm{CO}_{2}$ did not change significantly during surgery, $\mathrm{PaCO}_{2}$ and $\mathrm{P}_{\mathrm{a}-\mathrm{ET}} \mathrm{CO}_{2}$ increased gradually with time during pneumoperitoneum in the Trendelenburg position, and both parameters showed greater increases in the elderly than in the middle-aged group. Simple linear regression analyses revealed significant correlations between age and $\mathrm{P}_{\mathrm{a}-\mathrm{ET}} \mathrm{CO}_{2}$ at T0 $(\mathrm{P}=0.018)$, T1 $(\mathrm{P}=0.006)$, T2 $(\mathrm{P}<0.001)$, and T3 $(\mathrm{P}=0.001)$. Linear mixed model analysis showed that $\mathrm{P}_{\mathrm{a}-\mathrm{ET}} \mathrm{CO}_{2}$ was associated statistically significantly with age and duration of pneumoperitoneum in the Trendelenburg position, but age and duration of pneumoperitoneum in the Trendelenburg position were not associated $(\mathrm{P}=0.090)$.

Conclusions: The magnitude of $\mathrm{P}_{\mathrm{a}-\mathrm{ET}} \mathrm{CO}_{2}$ during pneumoperitoneum in the steep Trendelenburg position increased with age, which could be attributed to age-related respiratory physiological changes. (Korean J Anesthesiol 2012; 63: 209-215)

Key Words: Age, Carbon dioxide, Pneumoperitoneum, Trendelenburg position.

Received: February 15, 2012. Revised: 1st, March 6, 2012; 2nd, March 26, 2012. Accepted: April 12, 2012.

Corresponding author: Jai-Hyun Hwang, M.D., Department of Anesthesiology and Pain Medicine, College of Medicine, University of Ulsan, Asan Medical Center, 388-1, Pungnap2-dong, Songpa-gu, Seoul 138-736, Korea. Tel: 82-2-3010-3859, Fax: 82-2-470-1363, E-mail: jhhwang@ amc.seoul.kr

(c) This is an open-access article distributed under the terms of the Creative Commons Attribution Non-Commercial License (http:// creativecommons.org/licenses/by-nc/3.0/), which permits unrestricted non-commercial use, distribution, and reproduction in any medium, provided the original work is properly cited. 


\section{Introduction}

Measurement of end-tidal carbon dioxide pressure $\left(\mathrm{P}_{\mathrm{ET}} \mathrm{CO}_{2}\right)$ by capnometry is a useful non-invasive method to estimate arterial carbon dioxide partial pressure $\left(\mathrm{P}_{\mathrm{a}} \mathrm{CO}_{2}\right)$ during general anesthesia. Several factors have been reported to affect $\mathrm{P}_{\mathrm{ET}} \mathrm{CO}_{2}$ and to increase the arterial to end-tidal carbon dioxide pressure gradient $\left(\mathrm{P}_{\mathrm{a}-\mathrm{ET}} \mathrm{CO}_{2}\right)$ [1]. For example, Trendelenburg positioning and $\mathrm{CO}_{2}$ pneumoperitoneum have been found to decrease functional residual capacity (FRC) and to increase dead space ventilation. These maneuvers, performed either alone or together, may affect $\mathrm{P}_{\mathrm{a}-\mathrm{ET}} \mathrm{CO}_{2}$ [2-4]. In addition, age has been found to contribute to an increase in $\mathrm{P}_{\mathrm{a}-\mathrm{ET}} \mathrm{CO}_{2}$ [2].

Robot-assisted laparoscopic surgery has become an alternative approach to open techniques in many surgical fields. Robot-assisted laparoscopic prostatectomy (RALP) was found to improve surgical outcomes and to reduce complications compared with open radical prostatectomy $[5,6]$. However, RALP requires pneumoperitoneum in the steep Trendelenburg position, which can cause significant changes in respiratory physiology. $\mathrm{P}_{\mathrm{a}-\mathrm{ET}} \mathrm{CO}_{2}$ was shown to increase gradually with time during pneumoperitoneum in the Trendelenburg position [7] and a rise in $\mathrm{P}_{\mathrm{a}-\mathrm{ET}} \mathrm{CO}_{2}$ has been observed in elderly patients during gynecologic laparoscopy surgery [8]. To the best of our knowledge, the relationship between age and $\mathrm{P}_{\mathrm{a}-\mathrm{ET}} \mathrm{CO}_{2}$ in the steep Trendelenburg position with pneumoperitoneum has not been determined. Therefore, we evaluated the correlation between age and $\mathrm{P}_{\mathrm{a}-\mathrm{ET}} \mathrm{CO}_{2}$ in patients undergoing RALP.

\section{Materials and Methods}

We enrolled 92 consecutive male patients (ASA physical status I and II) undergoing elective RALP between May to December 2009. Patients with cardiopulmonary disease and/ or abnormal pulmonary function test results were excluded. Patients were divided into 2 groups by age; a middle-aged group (45-65 years) and an elderly group (> 65 years). The study protocol was approved by our Institutional Review Board, and all patients provided written informed consent.

All patients were premedicated with oral midazolam (7.5 mg) $1 \mathrm{~h}$ before induction of anesthesia. Upon arrival in the operating room, patients were monitored by ECG, pulse oximetry, and non-invasive automated arterial blood pressure tracking. Anesthesia was induced with thiopental $(4-5 \mathrm{mg} / \mathrm{kg})$ and vecuronium $(0.1 \mathrm{mg} / \mathrm{kg})$, and the trachea was intubated with an 8.0-mm endotracheal tube. Anesthesia was continued using sevoflurane (1-1.5 MAC) and additional boluses of vecuronium $(1-2 \mathrm{mg})$ and fentanyl $(1-1.5 \mu \mathrm{g} / \mathrm{kg})$ to maintain stable hemodynamic parameters (i.e., heart rate and blood pressure variations $<20 \%$ of preinduction values).
The lungs were ventilated with a ventilator (Primus; Dräger Medical, Lübeck, Germany) operating in the volume control mode. Ventilator settings were a tidal volume of $10 \mathrm{ml} / \mathrm{kg}$, an inspiratory: expiratory ratio of $1: 2$, a fraction of inspired $\mathrm{O}_{2}$ $\left(\mathrm{F}_{\mathrm{I}} \mathrm{O}_{2}\right)$ of 0.5 , and an air and inspiratory fresh gas flow of $2 \mathrm{~L} /$ min. The respiratory rate was adjusted to hold the $\mathrm{P}_{\mathrm{ET}} \mathrm{CO}_{2}$ between 30 and $38 \mathrm{mmHg}$. The end-tidal concentration of anesthesia gases and $\mathrm{P}_{\mathrm{ET}} \mathrm{CO}_{2}$ were monitored using the side stream method (M1026B Anesthetic Gas Module; Philips, Boeblingen, Germany).

After induction of anesthesia, a 20-G radial arterial catheter was inserted to obtain hemodynamic measurements and to permit blood sampling. Normothermia (about $36^{\circ} \mathrm{C}$ ) was maintained using a forced-air warming system. The abdominal cavity was insufflated with $\mathrm{CO}_{2}$ gas at a pressure of $15 \mathrm{mmHg}$, and the trocar and cannulae were located at the classical points [9] in the supine position. Each patient was slowly moved into a steep Trendelenburg position $\left(30^{\circ}\right.$ from horizontal; the maximal angle allowed by the operating table). RALPs were performed using the da Vinci Robot Surgical System (Intuitive Surgical, Sunnyvale, CA). Intra-abdominal pressure was automatically maintained at 10-13 mmHg. At the end of the procedure, each patient was returned to the supine position and the $\mathrm{CO}_{2}$ pneumoperitoneum was released. When the operation had completed, the patient was awakened and extubated in the operating room.

Heart rate, mean arterial pressure, peak inspiratory pressure, lung compliance, minute ventilation, and $\mathrm{P}_{\mathrm{ET}} \mathrm{CO}_{2}$ were measured 10 min after intubation in the supine position without pneumoperitoneum (T0; baseline); and 10 (T1), 60 (T2), and 120 (T3) min after pneumoperitoneum in the $30^{\circ}$ Trendelenburg position. Arterial oxygen partial pressure $\left(\mathrm{P}_{\mathrm{a}} \mathrm{O}_{2}\right)$ and $\mathrm{P}_{\mathrm{a}} \mathrm{CO}_{2}$ were measured by arterial blood gas analysis (GEM Premier 3000; Instrumentation Laboratory, Lexington, MA) at each time point. $\mathrm{P}_{\mathrm{a}-\mathrm{ET}} \mathrm{CO}_{2}$ was calculated as the difference between the measured $\mathrm{P}_{\mathrm{a}} \mathrm{CO}_{2}$ and $\mathrm{P}_{\mathrm{ET}} \mathrm{CO}_{2}$.

Based on a preliminary study, we estimated that data from 84 patients were required to detect a correlation coefficient above 0.3 between age and $\mathrm{P}_{\mathrm{a}-\mathrm{ET}} \mathrm{CO}_{2}$, with a statistical power of $80 \%$ and a type I error of 0.05 (the null hypothesis correlation is 0.0 and the alternative hypothesis correlation 0.3 ). To compensate for possible exclusions (10\%), 92 patients were enrolled in the present study. All statistical analyses were performed using SPSS for Windows Version 18.0 (SPSS Inc., Chicago, IL). Data are expressed as mean \pm SD. Changes in parameters (heart rate, mean arterial pressure, peak inspiratory pressure, lung compliance, minute ventilation, $\mathrm{P}_{\mathrm{a}} \mathrm{O}_{2}, \mathrm{P}_{\mathrm{ET}} \mathrm{CO}_{2}, \mathrm{P}_{\mathrm{a}} \mathrm{CO}_{2}$, and $\mathrm{P}_{\mathrm{a}-}$ ${ }_{\mathrm{ET}} \mathrm{CO}_{2}$ ) over time were assessed using a linear mixed model to evaluate within- and between-group differences. The relationship between age and $\mathrm{P}_{\mathrm{a}-\mathrm{ET}} \mathrm{CO}_{2}$ at each time point was determined using the Pearson correlation test and by 
performing a simple linear regression analysis. In addition, the relationships and interactions between $\mathrm{P}_{\mathrm{a}-\mathrm{ET}} \mathrm{CO}_{2}$ and patient or anesthetic parameters (age, body mass index, heart rate, mean arterial pressure, minute ventilation, peak inspiratory pressure, and $\mathrm{P}_{\mathrm{a}} \mathrm{O}_{2}$ ) with time (duration of pneumoperitoneum in the Trendelenburg position) were tested using a linear mixed model with adjustment for heart rate, mean arterial pressure, peak inspiratory pressure, minute ventilation, and $\mathrm{P}_{\mathrm{a}} \mathrm{O}_{2}$. A $\mathrm{P}$ value less than 0.05 was considered statistically significant.

\section{Results}

Ninety-two male patients were enrolled (46 in the middleaged group and 46 in the elderly group). No patient was excluded from the study. The numbers of data sets were 92 from T0, T1, and T2; and 84 from T3. Data sets were not collected from 8 patients at T3 ( 4 in either group) because the procedures were completed within $120 \mathrm{~min}$. Except for age, there was no significant between-group difference in any physical characteristic or surgical duration (Table 1).

Table 1. Patient Characteristics and Perioperative Data

\begin{tabular}{lcc}
\hline & Middle-aged $(\mathrm{n}=46)$ & Elderly $(\mathrm{n}=46)$ \\
\hline Age $(\mathrm{yr})$ & $59 \pm 5(49-65)$ & $70 \pm 3(66-78)^{*}$ \\
Weight $(\mathrm{kg})$ & $69 \pm 8(51-93)$ & $67 \pm 8(50-84)$ \\
Height $(\mathrm{cm})$ & $166 \pm 6(150-183)$ & $24 \pm 2(17-28)$ \\
Body mass index $\left(\mathrm{kg} / \mathrm{m}^{2}\right)$ & $25 \pm 2(21-30)$ & $267 \pm 49(162-360)$ \\
Anesthesia time $(\mathrm{min})$ & $265 \pm 47(177-392)$ & $212 \pm 44(125-295)$ \\
Operation time (min) & $215 \pm 44(130-320)$ & $165 \pm 43(87-238)$ \\
Trendelenburg position time (min) & $163 \pm 43(85-284)$ & $180 \pm 42(101-262)$ \\
Pneumoperitoneum time (min) & $179 \pm 44(95-296)$ & \\
\hline
\end{tabular}

Values are mean \pm SD (range). $* \mathrm{P}<0.05$ compared with the middle-aged group.

Table 2. Changes in Hemodynamic Parameters

\begin{tabular}{|c|c|c|c|c|c|}
\hline & Group & T0 & $\mathrm{T} 1$ & $\mathrm{~T} 2$ & T3 \\
\hline \multirow[t]{2}{*}{ Heart rate (beats/min) } & Middle-aged & $78.0 \pm 15.7$ & $65.5 \pm 10.1^{*}$ & $63.7 \pm 11.8^{*}$ & $67.6 \pm 8.2^{*}$ \\
\hline & Elderly & $75.8 \pm 14.4$ & $64.5 \pm 10.9 *$ & $63.8 \pm 10.0^{*}$ & $65.6 \pm 10.0 *$ \\
\hline \multirow[t]{2}{*}{ Mean arterial pressure (mmHg) } & Middle-aged & $92.9 \pm 18.9$ & $99.2 \pm 11.9 *$ & $89.8 \pm 8.4^{*}$ & $88.6 \pm 7.8^{*}$ \\
\hline & Elderly & $94.0 \pm 14.0$ & $98.2 \pm 12.8 *$ & $88.9 \pm 9.6^{*}$ & $88.8 \pm 9.8 *$ \\
\hline
\end{tabular}

Values are mean \pm SD. T0: 10 min after intubation in the supine position without pneumoperitoneum, T1: 10 min after pneumoperitoneum in the Trendelenburg position, T2: 60 min after pneumoperitoneum in the Trendelenburg position, T3: 120 min after pneumoperitoneum in the Trendelenburg position. $* \mathrm{P}<0.05$ compared with baseline (T0).

Table 3. Changes in Respiratory Parameters

\begin{tabular}{|c|c|c|c|c|c|}
\hline & Group & T0 & $\mathrm{T} 1$ & $\mathrm{~T} 2$ & T3 \\
\hline \multirow[t]{2}{*}{$\mathrm{P}_{\mathrm{ET}} \mathrm{CO}_{2}(\mathrm{mmHg})$} & Middle-aged & $30.5 \pm 2.7$ & $30.0 \pm 2.0$ & $30.0 \pm 1.7$ & $30.3 \pm 1.6$ \\
\hline & Elderly & $30.2 \pm 2.5$ & $30.0 \pm 2.0$ & $30.8 \pm 2.1$ & $30.7 \pm 1.6$ \\
\hline \multirow{2}{*}{$\mathrm{P}_{\mathrm{a}} \mathrm{CO}_{2}(\mathrm{mmHg})$} & Middle-aged & $38.3 \pm 2.5$ & $39.4 \pm 3.0$ & $40.5 \pm 3.1^{*}$ & $41.8 \pm 3.2^{*}$ \\
\hline & Elderly & $38.9 \pm 3.6$ & $40.7 \pm 3.1^{*, \dagger}$ & $43.5 \pm 3.5^{*, \dagger}$ & $44.0 \pm 3.4^{*, \dagger}$ \\
\hline \multirow{2}{*}{$\mathrm{P}_{\mathrm{a}-\mathrm{ET}} \mathrm{CO}_{2}(\mathrm{mmHg})$} & Middle-aged & $7.8 \pm 2.5$ & $9.5 \pm 2.4^{*}$ & $10.5 \pm 2.6^{*}$ & $11.5 \pm 2.5^{*}$ \\
\hline & Elderly & $8.8 \pm 2.7$ & $10.8 \pm 2.3^{*, \dagger}$ & $12.8 \pm 2.9^{*, \dagger}$ & $13.4 \pm 2.9^{*, \dagger}$ \\
\hline \multirow[t]{2}{*}{$\mathrm{P}_{\mathrm{a}} \mathrm{O}_{2}(\mathrm{mmHg})$} & Middle-aged & $254.3 \pm 28.5$ & $174.8 \pm 47.3^{*}$ & $174.0 \pm 43.5^{*}$ & $180.8 \pm 43.5^{*}$ \\
\hline & Elderly & $228.8 \pm 33.8^{\dagger}$ & $153.8 \pm 44.3^{*, \dagger}$ & $150.8 \pm 42.8^{*, \dagger}$ & $155.3 \pm 40.5^{*, \dagger}$ \\
\hline \multirow[t]{2}{*}{ Peak inspiratory pressure $\left(\mathrm{cmH}_{2} \mathrm{O}\right)$} & Middle-aged & $13.4 \pm 1.9$ & $29.2 \pm 3.9^{*}$ & $29.1 \pm 4.2^{*}$ & $29.5 \pm 2.9^{*}$ \\
\hline & Elderly & $13.8 \pm 2.4$ & $29.5 \pm 4.2^{*}$ & $29.7 \pm 4.4^{*}$ & $29.6 \pm 4.8^{*}$ \\
\hline \multirow{2}{*}{ Lung compliance $\left(\mathrm{ml} / \mathrm{cmH}_{2} \mathrm{O}\right)$} & Middle-aged & $52.2 \pm 7.6$ & $24.0 \pm 3.9 *$ & $24.1 \pm 3.6^{*}$ & $23.7 \pm 3.6^{*}$ \\
\hline & Elderly & $50.0 \pm 8.0$ & $23.0 \pm 3.2^{*}$ & $23.0 \pm 3.6^{*}$ & $23.2 \pm 4.1^{*}$ \\
\hline \multirow[t]{2}{*}{ Minute ventilation (L/min) } & Middle-aged & $6.9 \pm 0.8$ & $7.9 \pm 1.0^{*}$ & $7.9 \pm 1.1^{*}$ & $8.2 \pm 1.1^{*}$ \\
\hline & Elderly & $6.7 \pm 0.8$ & $7.7 \pm 1.0^{*}$ & $7.9 \pm 1.0^{*}$ & $8.0 \pm 1.1^{*}$ \\
\hline
\end{tabular}

Values are mean \pm SD. T0: 10 min after intubation in the supine position without pneumoperitoneum, T1: 10 min after pneumoperitoneum in the Trendelenburg position, T2: 60 min after pneumoperitoneum in the Trendelenburg position, T3: 120 min after pneumoperitoneum in the Trendelenburg position. ${ }^{*} \mathrm{P}<0.05$ compared with baseline (T0). ${ }^{\dagger} \mathrm{P}<0.05$ compared with the middle-aged group at the same time point. 
Hemodynamic data are shown in Table 2. Heart rate and mean arterial pressure changed significantly after pneumoperitoneum in the steep Trendelenburg position (from $\mathrm{T} 1$ to T3) compared with the baseline values at T0 in both groups, with no significant between-group difference being evident.

Table 3 shows changes in peak inspiratory pressure, lung compliance, minute ventilation, $\mathrm{P}_{\mathrm{a}} \mathrm{O}_{2}, \mathrm{P}_{\mathrm{ET}} \mathrm{CO}_{2}, \mathrm{P}_{\mathrm{a}} \mathrm{CO}_{2}$, and $\mathrm{P}_{\mathrm{a}}$ ${ }_{\mathrm{ET}} \mathrm{CO}_{2}$ at each time point. There was no significant between-group difference in any of peak inspiratory pressure, lung compliance, minute ventilation, or $\mathrm{P}_{\mathrm{ET}} \mathrm{CO}_{2}$. After $\mathrm{CO}_{2}$ insufflation in the steep Trendelenburg position, these values, except for $\mathrm{P}_{\mathrm{ET}} \mathrm{CO}_{2}$, changed significantly compared with the baseline values at $\mathrm{T} 0$. In addition, $\mathrm{P}_{\mathrm{a}} \mathrm{O}_{2}, \mathrm{P}_{\mathrm{a}} \mathrm{CO}_{2}$, and $\mathrm{P}_{\mathrm{a}-\mathrm{ET}} \mathrm{CO}_{2}$ changed significantly from $\mathrm{T} 0$ after $\mathrm{CO}_{2}$ insufflation in the steep Trendelenburg position, with all 3 parameters showing significant between-group differences.

A

TO

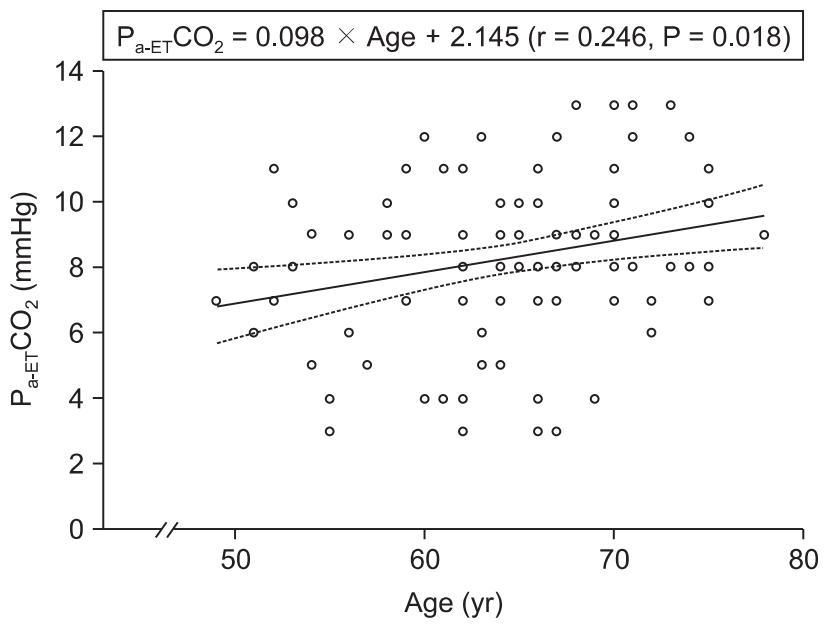

C

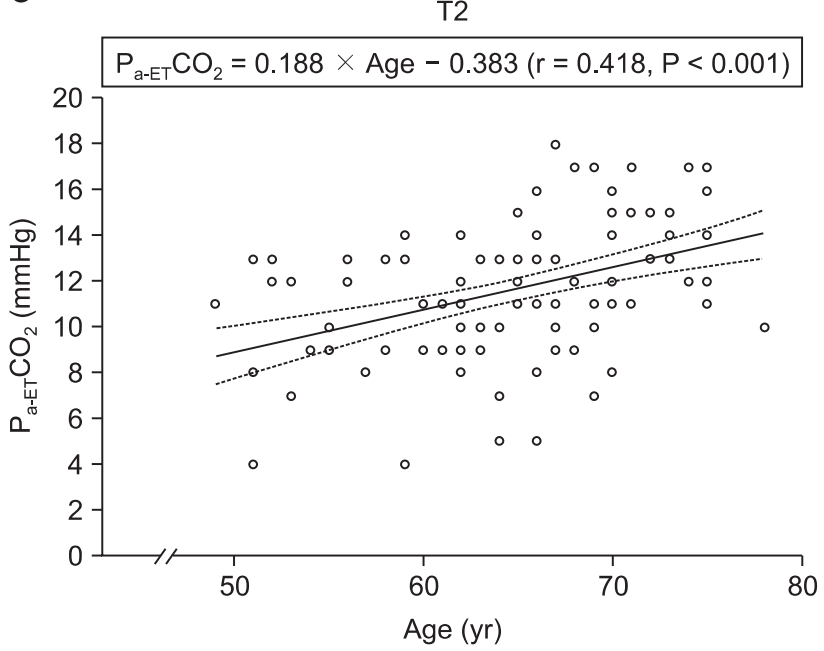

Although $\mathrm{P}_{\mathrm{ET}} \mathrm{CO}_{2}$ was maintained constant throughout surgery, $\mathrm{P}_{\mathrm{a}} \mathrm{CO}_{2}$ and $\mathrm{P}_{\mathrm{a}-\mathrm{ET}} \mathrm{CO}_{2}$ increased gradually with time during pneumoperitoneum in the steep Trendelenburg position. The magnitudes of these increases were significantly greater in the elderly than in the middle-aged group (Table 3).

We observed a significant correlation between age and $\mathrm{P}_{\mathrm{a}}$ ${ }_{\mathrm{ET}} \mathrm{CO}_{2}$ at each time point (Fig. 1). The regression coefficients were $0.098(\mathrm{P}=0.018)$ at $\mathrm{T} 0,0.105(\mathrm{P}=0.006)$ at $\mathrm{T} 1,0.188(\mathrm{P}<$ $0.001)$ at $\mathrm{T} 2$, and $0.150(\mathrm{P}=0.001)$ at $\mathrm{T} 3$.

A linear mixed model was used to evaluate the relationships and interactions between $\mathrm{P}_{\mathrm{a}-\mathrm{ET}} \mathrm{CO}_{2}$ and patient or anesthetic factors (age, body mass index, heart rate, mean arterial pressure, minute ventilation, peak inspiratory pressure, and $\mathrm{P}_{\mathrm{a}} \mathrm{O}_{2}$ ) with respect to duration of pneumoperitoneum in the Trendelenburg position, because of the absence of some T3 data sets. We
B

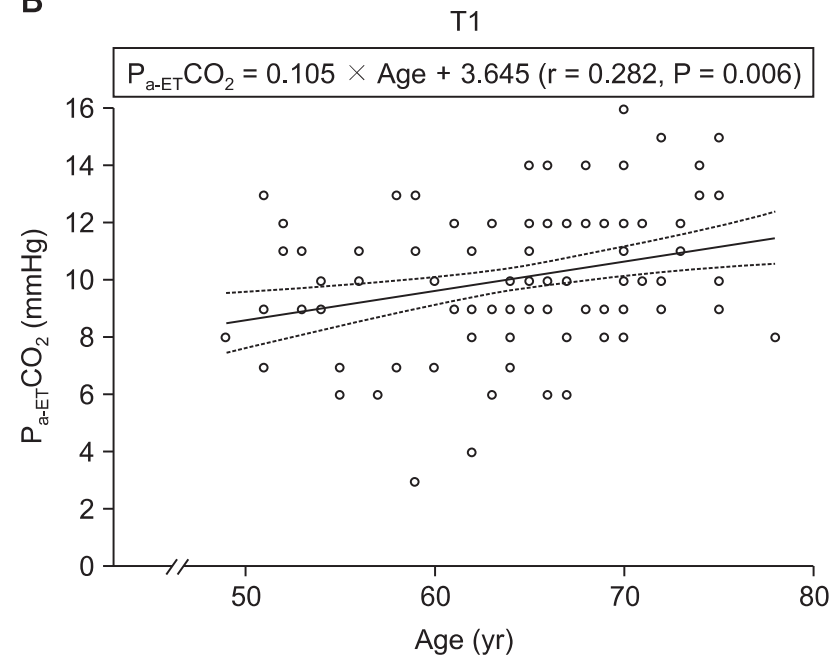

D

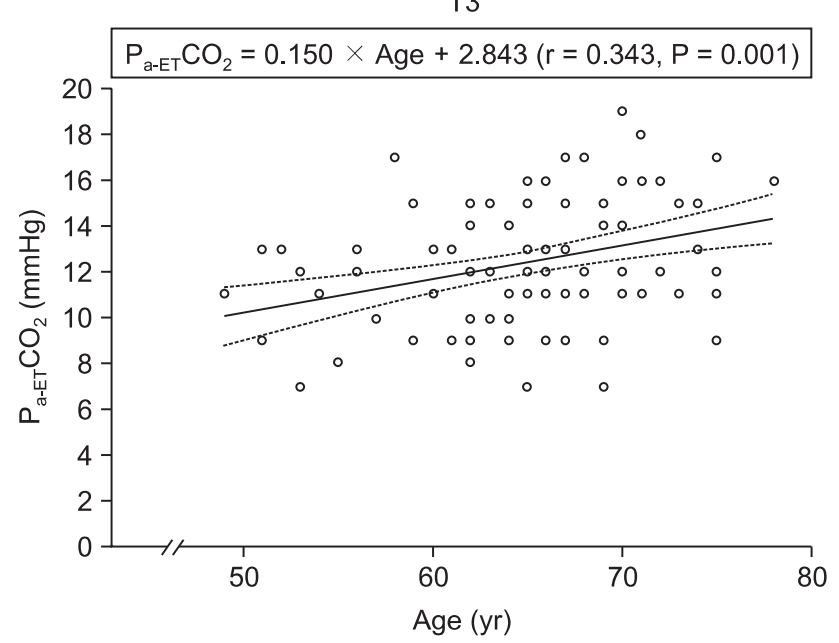

Fig. 1. Relationship between age and the arterial to end-tidal carbon dioxide pressure gradient $\left(\mathrm{P}_{\mathrm{a}-\mathrm{ET}} \mathrm{CO}_{2}\right)$ in $(\mathrm{A})$ the supine position without pneumoperitoneum, and (B) $10 \mathrm{~min}$, (C) $60 \mathrm{~min}$, and (D) $120 \mathrm{~min}$ after pneumoperitoneum in the Trendelenburg position. The lines show the linear regression relationships with $95 \%$ confidence intervals. 
Table 4. Factors Associated with the Arterial to End-tidal Carbon Dioxide Pressure Gradient $\left(\mathrm{P}_{\mathrm{a}-\mathrm{ET}} \mathrm{CO}_{2}\right)$

\begin{tabular}{lccc}
\hline \multirow{2}{*}{ Effect } & & $\mathrm{P}_{\mathrm{a} \text {-ET }} \mathrm{CO}_{2}$ & \\
\cline { 2 - 4 } & Unstandardized coefficient (B) & $95 \%$ confidence interval of B & 0.163 \\
\hline Intercept & 6.008 & $-2.453-14.461$ & \\
Time & 0 & & 0.027 \\
T0 & 2.280 & $0.263-4.290$ & 0.001 \\
T1 & 3.668 & $1.598-5.745$ & 0.001 \\
T2 & 4.500 & $2.430-6.563$ & 0.001 \\
T3 & 0.113 & $0.045-0.173$ & 0.746 \\
Age & -0.045 & $-0.300-0.218$ & 0.935 \\
Body mass index & 0 & $-0.023-0.023$ & 0.415 \\
Heart rate & -0.008 & $-0.030-0.015$ & 0.098 \\
Mean arterial pressure & -0.098 & $-0.218-0.015$ & 0.524 \\
Peak inspiratory pressure & 0.030 & $-0.113-0.060$ & 0.663 \\
Lung compliance & 0.113 & $-0.405-0.638$ & 0.337 \\
Minute ventilation & -0.030 & $-0.098-0.030$ & \\
$\mathrm{P}_{\mathrm{a}} \mathrm{O}_{2}$ & & & \\
\hline
\end{tabular}

The relationships and interactions between $\mathrm{P}_{\mathrm{a}-\mathrm{ET}} \mathrm{CO}_{2}$ and patient or anesthetic factors (age, body mass index, heart rate, mean arterial pressure, peak inspiratory pressure, minute ventilation, and $\mathrm{P}_{\mathrm{a}} \mathrm{O}_{2}$ ) with time were tested using a linear mixed model with adjustment for heart rate, mean arterial pressure, peak inspiratory pressure, minute ventilation, and $\mathrm{P}_{\mathrm{a}} \mathrm{O}_{2} \cdot \mathrm{P}_{\mathrm{a}-\mathrm{ET}} \mathrm{CO}_{2}$ was significantly related to patient age and duration of pneumoperitoneum in the Trendelenburg position, but age was not significantly related to duration of pneumoperitoneum in the Trendelenburg position $(\mathrm{P}=0.090)$. T0: $10 \mathrm{~min}$ after intubation in the supine position without pneumoperitoneum, T1: $10 \mathrm{~min}$ after pneumoperitoneum in the Trendelenburg position, T2: $60 \mathrm{~min}$ after pneumoperitoneum in the Trendelenburg position, T3: 120 min after pneumoperitoneum in the Trendelenburg position. $\mathrm{P}_{\mathrm{a}} \mathrm{O}_{2}$ arterial oxygen partial pressure.

found that $\mathrm{P}_{\mathrm{a}-\mathrm{ET}} \mathrm{CO}_{2}$ was significantly associated with patient age (regression coefficient $0.113, \mathrm{P}=0.001$ ) and with duration of pneumoperitoneum in the Trendelenburg position (regression coefficient 2.280, $\mathrm{P}=0.027$ at $\mathrm{T} 1$; regression coefficient $3.668, \mathrm{P}$ $=0.001$ at $\mathrm{T} 2$; and regression coefficient $4.500, \mathrm{P}<0.001$ at T3) (Table 4). However, there was no significant interaction between age and duration of pneumoperitoneum in the Trendelenburg position $(\mathrm{P}=0.090)$.

\section{Discussion}

We have shown here that $\mathrm{P}_{\mathrm{a}-\mathrm{ET}} \mathrm{CO}_{2}$ increased more in elderly than in middle-aged males during placement in the steep Trendelenburg position with $\mathrm{CO}_{2}$ pneumoperitoneum, and that a significant relationship between age and $\mathrm{P}_{\mathrm{a}-\mathrm{ET}} \mathrm{CO}_{2}$ in male patients undergoing RALP was evident.

RALP has several advantages compared with open retropubic radical prostatectomy, including easier accessibility, decreased blood loss, reduced postoperative pain, and a lower complication rate [6]. However, RALP requires pneumoperitoneum and Trendelenburg positioning, both of which, either alone or in combination, affect $\mathrm{P}_{\mathrm{a}-\mathrm{ET}} \mathrm{CO}_{2}$ [2-4]. A cephalad displacement of diaphragm resulting from $\mathrm{CO}_{2}$ pneumoperitoneum and placement in the steep Trendelenburg position enhances atelectasis formation, decreases lung volume and lung compliance [10-12]. The resultant enhancement of atelectasis formation may lead to increase in $\mathrm{P}_{\mathrm{a}-\mathrm{ET}} \mathrm{CO}_{2}$. This is supported by previous reports that $\mathrm{P}_{\mathrm{a}-\mathrm{ET}} \mathrm{CO}_{2}$ was a good predictor of atelectasis formation, and the absorption of $\mathrm{CO}_{2}$ during pneumoperitoneum had no effect on $\mathrm{P}_{\mathrm{a}-\mathrm{ET}} \mathrm{CO}_{2}$ [13].

Increases in $\mathrm{P}_{\mathrm{a}-\mathrm{ET}} \mathrm{CO}_{2}$ have been reported during pneumoperitoneum in the Trendelenburg position. For example, men undergoing RALP showed a mean $3.0 \mathrm{mmHg}$ increase in $\mathrm{P}_{\mathrm{a}-\mathrm{ET}} \mathrm{CO}_{2}$ after $120 \mathrm{~min}$ in the steep Trendelenburg position with $\mathrm{CO}_{2}$ pneumoperitoneum [4], and women undergoing laparoscopic hysterectomy in the Trendelenburg position showed a mean $1.5 \mathrm{mmHg}$ increase in $\mathrm{P}_{\mathrm{a}-\mathrm{ET}} \mathrm{CO}_{2}$ [3]. In addition, $\mathrm{P}_{\mathrm{ET}} \mathrm{CO}_{2}$ differed significantly from $\mathrm{P}_{\mathrm{a}} \mathrm{CO}_{2}$ during prolonged laparoscopic colon surgery in the Trendelenburg position [7]. We observed a mean $4.1 \mathrm{mmHg}$ increase in $\mathrm{P}_{\mathrm{a}-\mathrm{ET}} \mathrm{CO}_{2}$ after 120 min of pneumoperitoneum and steep Trendelenburg positioning. Moreover, linear mixed model analysis showed a significant relationship between $\mathrm{P}_{\mathrm{a}-\mathrm{ET}} \mathrm{CO}_{2}$ and duration of pneumoperitoneum in the Trendelenburg position. Our results are consistent with previous findings showing that $\mathrm{P}_{\mathrm{a}-\mathrm{ET}} \mathrm{CO}_{2}$ increased during pneumoperitoneum in the Trendelenburg position $[3,4]$, although both studies in the nature of surgery and patient characteristics. Our results indicate that measurements of $\mathrm{P}_{\mathrm{ET}} \mathrm{CO}_{2}$ may underestimate $\mathrm{P}_{\mathrm{a}} \mathrm{CO}_{2}$ under certain circumstances, and that ventilator settings based on capnometry in anesthetized patients should be carefully determined.

$\mathrm{P}_{\mathrm{a}-\mathrm{ET}} \mathrm{CO}_{2}$ during general anesthesia has been reported to be affected by age. For example, significant correlations were observed between age and $\mathrm{P}_{\mathrm{a}-\mathrm{ET}} \mathrm{CO}_{2}$ in patients in the supine, lateral, prone, and Trendelenburg positions [2]. In the cited 
study, the relationship between age and $\mathrm{P}_{\mathrm{a}-\mathrm{ET}} \mathrm{CO}_{2}$ was assessed separately in supine patients and those in the Trendelenburg groups, whereas we assessed the relationship at different time points in patients placed in the Trendelenburg position. Moreover, $\mathrm{P}_{\mathrm{a}-\mathrm{ET}} \mathrm{CO}_{2}$ was found to increase gradually after $\mathrm{CO}_{2}$ pneumoperitoneum in the Trendelenburg position only in elderly patients [8]. Although the cited study compared $\mathrm{P}_{\mathrm{a}-\mathrm{ET}} \mathrm{CO}_{2}$ between elderly patients and those of other age groups at the same time point, the work did not evaluate the relationship between age and $\mathrm{P}_{\mathrm{a}-\mathrm{ET}} \mathrm{CO}_{2}$. In contrast, we found that the magnitude of the increase in $\mathrm{P}_{\mathrm{a}-\mathrm{ET}} \mathrm{CO}_{2}$ was significantly greater in elderly than in middle-aged men, and linear mixed model analysis showed a significant relationship between age and $\mathrm{P}_{\mathrm{a}-\mathrm{ET}} \mathrm{CO}_{2}$. Although differences in study design are evident, our results are in agreement with previous findings showing that $\mathrm{P}_{\mathrm{a}-\mathrm{ET}} \mathrm{CO}_{2}$ increases with age in patients under general anesthesia $[2,8]$.

In addition, we used linear mixed model analysis to assess the relationships and interactions between $\mathrm{P}_{\mathrm{a}-\mathrm{ET}} \mathrm{CO}_{2}$ and patient or anesthetic factors, on the one hand, and duration of pneumoperitoneum in the Trendelenburg position, on the other. This analysis showed that the magnitude of $\mathrm{P}_{\mathrm{a}-\mathrm{ET}} \mathrm{CO}_{2}$ was significantly related to both age and duration of pneumoperitoneum in the Trendelenburg position. However, the interaction between age and duration of pneumoperitoneum in the Trendelenburg position was not significant. These results suggest that aging may increase $\mathrm{P}_{\mathrm{a}-\mathrm{ET}} \mathrm{CO}_{2}$ during general anesthesia, with or without pneumoperitoneum in the Trendelenburg position.

The possible mechanism of higher gradient in the elderly group is unclear, but it may be explained by the age-related respiratory changes. It is well known that aging is intimately associated with various changes in the respiratory system, including structural and functional changes in the lungs. In terms of lung volume, aging increases residual volume, closing volume, and FRC [14]. Although atelectasis does not increase with age during general anesthesia, the amount of perfusion to low ventilation/perfusion regions increases with age due to increased airway closure $[15,16]$. Therefore, these age-related changes in respiratory function are likely to increase $\mathrm{P}_{\mathrm{a}-\mathrm{ET}} \mathrm{CO}_{2}$ during general anesthesia.

The magnitude of $\mathrm{P}_{\mathrm{a}-\mathrm{ET}} \mathrm{CO}_{2}$ is influenced by many factors, including pulmonary disorders, anesthesia, and cardiac output $[1,17,18]$. To minimize the effects of such factors, we included only healthy patients without cardiopulmonary disease and/ or abnormal pulmonary function test results. In addition, anesthetic management was standardized in terms of anesthetic drugs, ventilator settings, and patient position. Thus, the effect of anesthetic conditions on $\mathrm{P}_{\mathrm{a}-\mathrm{ET}} \mathrm{CO}_{2}$ may be expected to be the same in all patients. Finally, cardiac output could change $\mathrm{P}_{\mathrm{a}} \mathrm{CO}_{2}$ and $\mathrm{P}_{\mathrm{ET}} \mathrm{CO}_{2}$ in the same direction, but the change in $\mathrm{P}_{\mathrm{a}-\mathrm{ET}} \mathrm{CO}_{2}$ is variable in direction and magnitude [19]. In addition, $\mathrm{P}_{\mathrm{a}-\mathrm{ET}} \mathrm{CO}_{2}$ remains stable when cardiac output is constant [20]. The steep Trendelenburg position with pneumoperitoneum was recently reported to cause no change in cardiac output during RALP $[21,22]$. Although cardiac output was not measured in the present study, the observed increase in $\mathrm{P}_{\mathrm{a}-\mathrm{ET}} \mathrm{CO}_{2}$ was not likely affected by this factor.

This study had several limitations. First, the data from our homogeneous group of patients may be specific to an older male population undergoing RALP. Because prostate cancer usually occurs in older men (mean age at diagnosis is 67 years) [23], all patients enrolled in this study were men with a narrower age range (49-78 years) and with a smaller mean age difference between the groups (11 years), when compared with previous studies $[2,7,8]$. Therefore, the gender and age range may limit the generalization of our data. Second, arterial blood gas analyses were not performed on patients in the Trendelenburg position or with pneumoperitoneum alone. In our institute, urologic surgeons perform $\mathrm{CO}_{2}$ insufflation before patients are placed in the Trendelenburg position. Therefore, additional time would have been required to analyze arterial blood gases in such patients, which would have unethically prolonged the duration of anesthetic management. Third, we did not conduct measurements in the non-anesthetized state because the impact of anesthesia on such parameters has been previously reported [3].

In conclusion, we found that the magnitude of $\mathrm{P}_{\mathrm{a}-\mathrm{ET}} \mathrm{CO}_{2}$ increased gradually with time during pneumoperitoneum in the steep Trendelenburg position, and rose with advancing patient age. Under such specific circumstances, ventilator settings based on capnometry in elderly patients should be carefully determined and $\mathrm{P}_{\mathrm{a}} \mathrm{CO}_{2}$ should be measured periodically by arterial blood sampling during surgery.

\section{Acknowledgments}

The authors would like to thank Dr. Hwa Jung Kim and Miss Seon Ok Kim of the Department of Clinical Epidemiology and Biostatistics, Asan Medical Center, for their assistance.

\section{References}

1. Bhavani-Shankar K, Moseley H, Kumar AY, Delph Y. Capnometry and anaesthesia. Can J Anaesth 1992; 39: 617-32.

2. Casati A, Salvo I, Torri G, Calderini E. Arterial to end-tidal carbon dioxide gradient and physiological dead space monitoring during general anaesthesia: effects of patients' position. Minerva Anestesiol 1997; 63: 177-82.

3. Hirvonen EA, Nuutinen LS, Kauko M. Ventilatory effects, blood gas changes, and oxygen consumption during laparoscopic 
hysterectomy. Anesth Analg 1995; 80: 961-6.

4. Kalmar AF, Foubert L, Hendrickx JF, Mottrie A, Absalom A, Mortier EP, et al. Influence of steep Trendelenburg position and $\mathrm{CO} 2$ pneumoperitoneum on cardiovascular, cerebrovascular, and respiratory homeostasis during robotic prostatectomy. $\mathrm{Br} \mathrm{J}$ Anaesth 2010; 104: 433-9.

5. Menon M, Shrivastava A, Tewari A. Laparoscopic radical prostatectomy: conventional and robotic. Urology 2005; 66(5 Suppl): 101-4.

6. Hegarty NJ, Kaouk JH. Radical prostatectomy: a comparison of open, laparoscopic and robot-assisted laparoscopic techniques. Can J Urol 2006; 13 Suppl 1: 56-61.

7. Klopfenstein CE, Schiffer E, Pastor CM, Beaussier M, Francis K, Soravia C, et al. Laparoscopic colon surgery: unreliability of endtidal CO2 monitoring. Acta Anaesthesiol Scand 2008; 52: 700-7.

8. Takahata O, Kunisawa T, Nagashima M, Mamiya K, Sakurai K, Fujita S, et al. Effect of age on pulmonary gas exchange during laparoscopy in the Trendelenburg lithotomy position. Acta Anaesthesiol Scand 2007; 51: 687-92.

9. Buffi N, Mottrie A, Lughezzani G, Koliakos N, Schatteman P, Carpentier P, et al. Surgery illustrated--Surgical Atlas. Robotic radical cystectomy in the male. BJU Int 2009; 104: 726-45.

10. Andersson LE, Baath M, Thorne A, Aspelin P, Odeberg-Wernerman S. Effect of carbon dioxide pneumoperitoneum on development of atelectasis during anesthesia, examined by spiral computed tomography. Anesthesiology 2005; 102: 293-9.

11. Strang CM, Freden F, Maripuu E, Hachenberg T, Hedenstierna G. Ventilation-perfusion distributions and gas exchange during carbon dioxide-pneumoperitoneum in a porcine model. Br J Anaesth 2010; 105: 691-7.

12. Suh MK, Seong KW, Jung SH, Kim SS. The effect of pneumoperitoneum and Trendelenburg position on respiratory mechanics during pelviscopic surgery. Korean J Anesthesiol 2010; 59: 329-34.
13. Strang CM, Hachenberg T, Freden F, Hedenstierna G. Development of atelectasis and arterial to end-tidal PCO2-difference in a porcine model of pneumoperitoneum. Br J Anaesth 2009; 103: 298-303.

14. Rossi A, Ganassini A, Tantucci C, Grassi V. Aging and the respiratory system. Aging (Milano) 1996; 8: 143-61.

15. Gunnarsson L, Tokics L, Gustavsson H, Hedenstierna G. Influence of age on atelectasis formation and gas exchange impairment during general anaesthesia. Br J Anaesth 1991; 66: 423-32.

16. Rothen HU, Sporre B, Engberg G, Wegenius G, Hedenstierna G. Airway closure, atelectasis and gas exchange during general anaesthesia. $\mathrm{Br} \mathrm{J}$ Anaesth 1998; 81: 681-6.

17. Whitesell R, Asiddao C, Gollman D, Jablonski J. Relationship between arterial and peak expired carbon dioxide pressure during anesthesia and factors influencing the difference. Anesth Analg 1981; 60: 508-12.

18. Shibutani K, Muraoka M, Shirasaki S, Kubal K, Sanchala VT, Gupte $\mathrm{P}$. Do changes in end-tidal PCO2 quantitatively reflect changes in cardiac output? Anesth Analg 1994; 79: 829-33.

19. Wahba RW, Tessler MJ, Beique F, Kleiman SJ. Changes in PCO2 with acute changes in cardiac index. Can J Anaesth 1996; 43: 243-5.

20. Sharma SK, McGuire GP, Cruise CJ. Stability of the arterial to endtidal carbon dioxide difference during anaesthesia for prolonged neurosurgical procedures. Can J Anaesth 1995; 42: 498-503.

21. Falabella A, Moore-Jeffries E, Sullivan MJ, Nelson R, Lew M. Cardiac function during steep Trendelenburg position and CO2 pneumoperitoneum for robotic-assisted prostatectomy: a transoesophageal Doppler probe study. Int J Med Robot 2007; 3: 312-5.

22. Meininger D, Westphal K, Bremerich DH, Runkel H, Probst M, Zwissler B, et al. Effects of posture and prolonged pneumoperitoneum on hemodynamic parameters during laparoscopy. World J Surg 2008; 32: 1400-5.

23. VanderWalde A, Hurria A. Aging and osteoporosis in breast and prostate cancer. CA Cancer J Clin 2011; 61: 139-56. 